\title{
Endothelin Action on Pituitary Lactotrophs: One Receptor, Many GTP-Binding Proteins
}

\author{
Richard Bertram, ${ }^{1,2 *}$ Joel Tabak, ${ }^{2 *}$ Natalia Toporikova, ${ }^{1 *}$ Marc E. Freeman ${ }^{2,3 *}$ \\ (Published 24 January 2006) \\ (Revised 7 February 2006)
}

The secretion of prolactin (PRL) from pituitary lactotrophs of the rat is predominantly under inhibitory control exerted by dopamine (DA) of hypothalamic origin (1). Other PRL-inhibiting substances of hypothalamic origin include somatostatin and endothelin (ET) (2). The latter is the focus of a recent article from the Stojilkovic lab (3) and of this report. In addition to the PRL-inhibiting substances, a host of candidate PRL-releasing hormones, also of hypothalamic origin, exist (2). These include thyrotropin-releasing hormone (TRH), vasoactive intestinal polypeptide, angiotensin II, oxytocin (OT), and even DA itself (2). Each has well-described receptors on the lactotroph membrane and, in most cases, has well-defined postreceptor transduction cascades that regulate PRL secretion. These include the activation of excitatory or inhibitory guanosine triphosphate (GTP)-binding proteins ( $\mathrm{G}$ proteins) $\left(\mathrm{G}_{\mathrm{s}}, \mathrm{G}_{\mathrm{q}}\right.$, and $\left.\mathrm{G}_{\mathrm{i} / \mathrm{o}}\right)$, which activate or inhibit adenylyl cyclase with downstream effects on adenosine $3^{\prime}, 5^{\prime}$-monophosphate (cAMP) formation or which activate phospholipase $\mathrm{C}$ (PLC). Although the nature of these pathways differs, they share one final common denominator: They each regulate PRL secretion by affecting the intracellular levels of calcium, the key ion evoking PRL exocytosis.

The ETs are a family of vasoconstrictor peptides that were found in (4) and later purified from tissue culture media of vascular endothelial cells (5). Three different ET isopeptides encoded by three separate genes were identified and designated ET-1, -2, and -3 (6). Similarly, three types of ET receptors have been identified and cloned (7-9). In pituitary cells, endothelins operate through $\mathrm{ET}_{\mathrm{A}}$ receptors, which have greater affinity for ET-1 and ET-2 than for ET-3 (10). Early evidence suggested that the ETs may affect pituitary hormone secretion. Indeed, their mRNAs are found in the pituitary gland and in hypothalamic magnocellular nuclei $(11,12)$. Moreover, ETs and their receptors are found in the anterior lobe of the pituitary gland (13), and ET-like immunoreactivity is found in lactotrophs, gonadotrophs, and somatotrophs (14). This suggests that the ETs may be autocrine regulators of pituitary hormone secretion (15).

Other lines of evidence indicate that the ETs play a role in the secretion of hormones from the anterior pituitary gland. It has been reported that ETs acting at $\mathrm{ET}_{\mathrm{A}}$ receptors (10) diminish PRL secretion while enhancing luteinizing hormone, follicle-stimulating hormone, and thyroid-stimulating hormone secretion in vitro $(16-18)$. In the presence of DA, the PRL secretory response to ET-1 is biphasic, consisting of an initial rapid high-amplitude stimulatory phase followed by a sustained modest elevation as long as ET-1 is present (19). In the absence of

\footnotetext{
${ }^{1}$ Department of Mathematics, ${ }^{2}$ Program in Neuroscience, ${ }^{3}$ Department of Biological Sciences, Florida State University, Tallahassee, FL 32306, USA.

*Corresponding authors. E-mail, bertram @ math.fsu.edu (R.B.); joel@neuro.fsu.edu (J.T.); ntoporik@math.fsu.edu (N.T.); freeman@neuro.fsu.edu (M.E.F.)
}

DA, the initial ET-mediated stimulatory response is followed by a sustained inhibition of PRL secretion, which lasts for tens of minutes after the removal of the ET-1 (19). The effect of ET-1 in lactotrophs is partially mediated by the activation of large-conductance $\mathrm{Ca}^{2+}$-activated $\mathrm{K}^{+}$channels $\left(\mathrm{BK}_{\mathrm{Ca}}\right)$. In the presence of DA, the effect of ET-1 on $\mathrm{BK}_{\mathrm{Ca}}$ channels is reversed from stimulatory to inhibitory (20). The presence of particular $\mathrm{G}$ proteins and their postreceptor coupling to $\mathrm{ET}_{\mathrm{A}}$ receptors may determine whether lactotrophs respond to ETs by increasing or decreasing intracellular $\mathrm{Ca}$ and thus excite or inhibit PRL secretion.

The biphasic PRL response to ET-1 is accompanied by a biphasic response in the intracellular $\mathrm{Ca}^{2+}$ concentration $\left(\left[\mathrm{Ca}^{2+}\right]_{\mathrm{i}}\right)$, suggesting that the PRL response is due, at least in part, to the $\mathrm{Ca}^{2+}$ response (21). This response can be mathematically modeled as illustrated in Fig. 1, A and B. The biphasic pattern of changes in $\mathrm{Ca}^{2+}$ concentration and PRL secretion in response to ET-1 reported by the Stojilkovic lab (an initial increase followed by a reduction to below baseline levels) was unusual and seemed to mimic the combined actions of TRH (the initial rise) (22) and DA (the sustained inhibition) (1). The initial transient increase in $\left[\mathrm{Ca}^{2+}\right]_{\mathrm{i}}$ was not due to $\mathrm{Ca}^{2+}$ influx, because it was not affected by the $\mathrm{Ca}^{2+}$-channel blocker nifedipine. Thus, the initial $\left[\mathrm{Ca}^{2+}\right]_{\mathrm{i}}$ spike was due to the release of $\mathrm{Ca}^{2+}$ from intracellular stores $(21)$, whereas the later sustained reduction in $\left[\mathrm{Ca}^{2+}\right]_{\mathrm{i}}$ was due to membrane hyperpolarization, which deactivates $\mathrm{Ca}^{2+}$ channels (21). Thus, ET-1 appeared to have at least two distinct effects on lactotrophs: one stimulatory and one inhibitory.

Following this work, the Stojilkovic lab focused on the signaling pathways mediating the effects of ET-1 in lactotrophs. ET-1 inhibited $\mathrm{Ca}^{2+}$ influx through a pertussis toxin (PTX)- sensitive $\mathrm{G}_{\mathrm{i} / \mathrm{o}}$ signaling pathway by activating inward rectifying $\mathrm{K}^{+}$(GIRK) channels, hyperpolarizing the cell (23). The initial rise in $\left[\mathrm{Ca}^{2+}\right]_{\mathrm{i}}$ was mediated by a $\mathrm{G}$ protein other than $\mathrm{G}_{\mathrm{i} / \mathrm{o}}$. The most recent data demonstrate that four different $G$ protein pathways (Fig. 2) mediate the effects of ET-1 in lactotrophs (3). The initial increase in $\left[\mathrm{Ca}^{2+}\right]_{\mathrm{i}}$ after the application of nanomolar concentrations of ET-1, and the initial increase in PRL secretion, are mediated by a $\mathrm{G}_{\mathrm{q}}$ pathway. This pathway has been well characterized: The $\mathrm{G}_{\mathrm{q}} \alpha$ subunit of the activated G protein activates PLC, catalyzing the hydrolysis of phosphatidylinositol 4,5-bisphosphate to inositol 1,4,5trisphosphate $\left(\mathrm{IP}_{3}\right)$ and diacylglycerol. The $\mathrm{IP}_{3}$ binds to receptors in the endoplasmic reticulum (ER) membrane, opening the channels and allowing $\mathrm{Ca}^{2+}$ to flow down its concentration gradient from the ER into the cytosol (Fig. 1, A and C) (24). The resulting spike in $\left[\mathrm{Ca}^{2+}\right]_{\mathrm{i}}$ produces a spike in PRL secretion (Fig. 1B).

The second pathway activated by ET- 1 is mediated by the heterodimer $\mathrm{G}_{\mathrm{i} / \mathrm{o}} \beta \gamma$. This signaling molecule acts directly on ion channels, inactivating $\mathrm{Ca}^{2+}$ channels $(25,26)$ and activating GIRK channels (27). Although there was no evidence for ET1 -mediated $\mathrm{Ca}^{2+}$ channel inhibition in lactotrophs, ET-1 activated GIRK channels $(3,23)$. Activation of these channels by $\mathrm{G}_{\mathrm{i} / \mathrm{o}} \mathrm{B} \gamma$ leads to membrane hyperpolarization (Fig. 1D), with a 
resulting deactivation of calcium channels and a decrease in $\left[\mathrm{Ca}^{2+}\right]_{\mathrm{i}}$ and PRL secretion (Fig. 1, A and B).

The third and fourth pathways of action of ET-1 are mediated by G proteins of the type $G_{z}$, a subfamily of $G_{i}$ that is resistant to PTX $(28,29)$. Both the $G_{z} \alpha$ and $G_{z} \beta \gamma$ arms of the activated $\mathrm{G}_{\mathrm{z}}$ protein play important roles in the response to nanomolar concentrations of ET-1 (3). Like $G_{i} \alpha, G_{z} \alpha$ inhibits adenylyl cyclase, thus reducing cellular cAMP levels (30). Andric et al. show that the application of ET-1 leads to a reduction in CAMP concentration in lactotrophs (Fig. 1E) and that this effect is resistant to PTX (3). The reduction in cAMP results in a decline in the activity of protein kinase A (PKA), a kinase with many potential targets, including the priming of vesicles for exocytosis (31). Thus, the finding of Andric et al. that PRL secretion declines when cAMP levels are reduced is consistent with what one would expect from a reduction in PKA activity. This inhibitory effect on secretion is downstream of $\mathrm{Ca}^{2+}$ entry, because ET-1 inhibits PRL secretion even when the $\mathrm{Ca}^{2+}$ levels are elevated (3). Also, when cAMP was elevated with forskolin (short-circuiting the effect of

Fig. 1. Mathematical modeling of the four $\mathrm{G}$ protein signaling pathways mediating the effects of nanomolar (nM) concentrations of ET-1 on a lactotroph. The mathematical model of the lactotroph can be downloaded from www.math.fsu.edu/ bertram/software/pituitary. Activation of $\mathrm{G}_{\mathrm{q}} \alpha$ results in the opening of $\mathrm{IP}_{3}$-sensitive $\mathrm{Ca}^{2+}$ channels in the ER membrane, allowing $\mathrm{Ca}^{2+}$ to flow downstream into the cytosol (A) from the ER (C). The resulting $\mathrm{Ca}^{2+}$ spike causes a spike in $\mathrm{PRL}$ secretion (B). Activation of $\mathrm{G}_{\mathrm{i} / \mathrm{o}} \beta \gamma$ hyperpolarizes the plasma membrane (D), leading to reductions in $\left[\mathrm{Ca}^{2+}\right]_{i}$ and $\mathrm{PRL}$ secretion. Activation of $\mathrm{G}_{\mathrm{z}} \alpha$ leads to a reduction in adenylyl cyclase activity and cAMP levels (E), with subsequent inhibition of secretion downstream of $\mathrm{Ca}^{2+}$ entry. This inhibition remains for tens of minutes after removal of the agonist (B). Liberation of $G_{z} \beta \gamma$ from the activated $G_{z}$ protein directly inhibits $P R L$ secretion (B), probably by binding to the SNARE vesicle fusion complex. This effect is terminated quickly when the agonist is removed. The values of all variables except membrane potential and time are in arbitrary units.
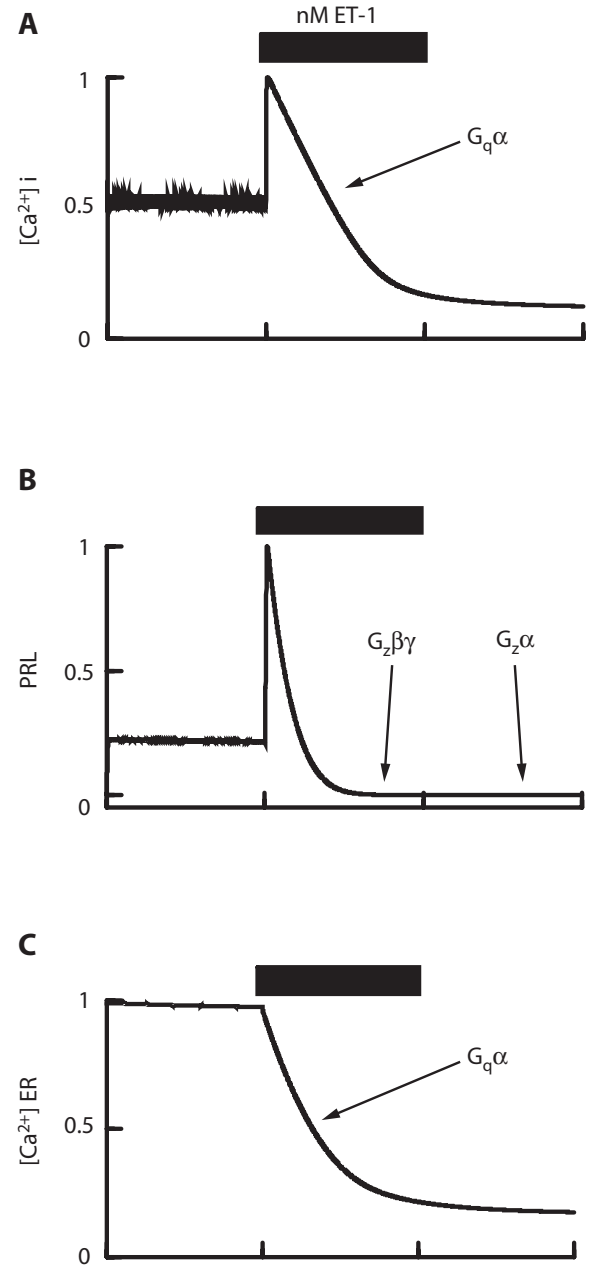

D

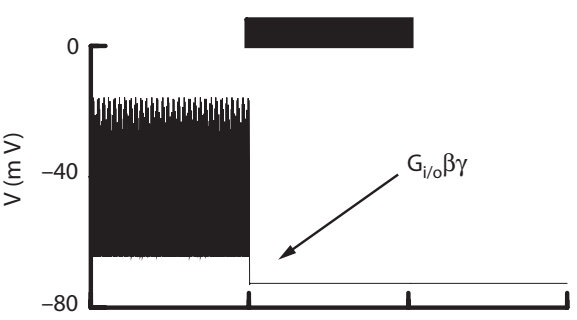

E

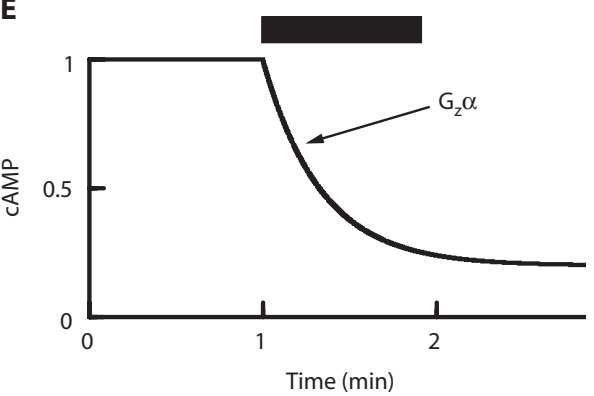

$G_{z} \alpha$ ), the inhibitory action of ET-1 on PRL secretion was not sustained but was rapidly terminated after the removal of ET-1 from the bath. This suggests that the pathway mediated by $G_{z} \alpha$ is responsible for the PRL inhibition that remains after the removal of ET-1 (Fig. 1B).

Andric et al. unmask the fourth pathway of ET-1 action by using picomolar concentrations of ET- 1 . These low concentrations have no effect on $\left[\mathrm{Ca}^{2+}\right]_{\mathrm{i}}$ (Fig. 3A) but nearly eliminate PRL secretion (Fig. 3B), even in the presence of PTX (3). PRL secretion is also reduced at picomolar concentrations of ET-1 when cAMP is elevated by forskolin. Together, these data suggest that the fourth pathway is downstream of $\mathrm{Ca}^{2+}$ entry, is PTX-resistant, and does not operate through inhibition of adenylyl cyclase. This leads Andric et al. to conclude that $G_{z} \beta \gamma$ is mediating the response and that it is directly inhibiting the exocytotic machinery. It has recently been demonstrated that $G$ protein $\beta \gamma$ dimers can directly inhibit secretion by binding to soluble $N$-ethylmaleimide-sensitive factor attachment protein receptor (SNARE) complexes $(32,33)$, which are key components of the vesicle fusion machinery. G $\beta \gamma$ competes with the $\mathrm{Ca}^{2+}$ sensor synaptotagmin for binding to SNARE complexes, thus reducing $\mathrm{Ca}^{2+}$-evoked exocytosis (32). This could very well be the mechanism for the fourth ET-1 inhibitory pathway in lactotrophs. Andric et al. show that this inhibitory action is terminated quickly after removal of the agonist ET-1, because PRL secretion returns to basal levels rapidly in the presence of forskolin (that is, when the $\mathrm{G}_{\mathrm{z}} \alpha$ pathway is short-circuited). Thus, the $G_{z} \beta \gamma$ pathway contributes to the inhibition of PRL secretion only while ET-1 is present (Fig. 1B).

The work of the Stojilkovic lab and others clearly demonstrates the capacity of $\mathrm{G}$ protein-coupled receptors to initiate a wide array of actions, some stimulatory and some inhibitory. What is the physiological purpose of the initial stimulatory action? To what extent are the inhibitory actions redundant? It seems unnecessary to hyperpolarize the lactotroph and directly inhibit secretion. Then again, hormones such as TRH or OT may act in concert with ET in physiological settings, and these 


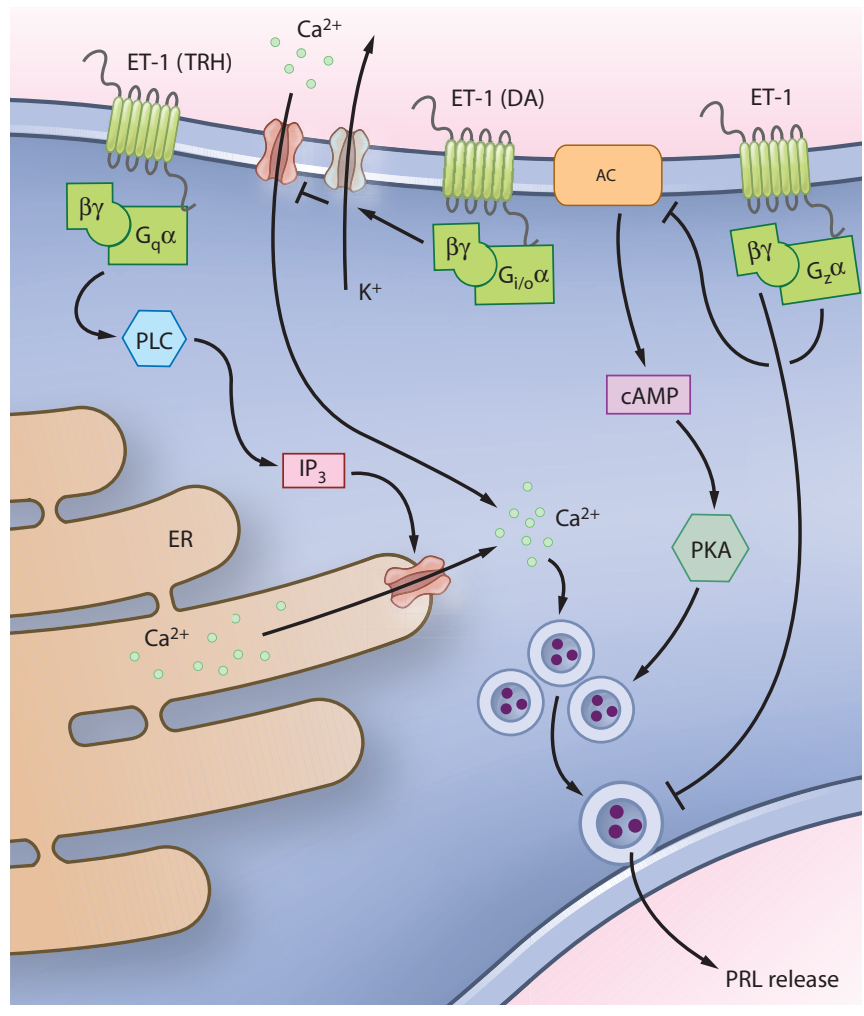

Fig. 2. ET-1 binding to $E T_{A}$ receptor activates at least four $G$ protein pathways. (Left) $G_{q} \alpha$ activates PLC, which leads to an increase in $\mathrm{IP}_{3}$, allowing $\mathrm{Ca}^{2+}$ to flow into the cytosol from the ER. This pathway (also activated by TRH) causes the initial spike in $\left[\mathrm{Ca}^{2+}\right]_{i}$ and PRL secretion. (Middle) $\mathrm{G}_{\mathrm{i} / \mathrm{o}} \beta \gamma$ activates GIRK channels, causing membrane hyperpolarization, which stops $\mathrm{Ca}^{2+}$ influx through voltage-gated channels. This pathway (also activated by DA binding on D2 receptors) results in a decrease of $\left[\mathrm{Ca}^{2+}\right]_{i}$ and thus of PRL secretion. (Right) Andric et al. also showed that a third $G$ protein, $G_{z}$, is coupled to $E_{A}$ receptors. Upon binding by ET-1, $G_{z} \alpha$ inhibits adenylyl cyclase, decreasing the cAMP concentration and ultimately decreasing $P R L$ release. In addition, $\mathrm{G}_{\mathrm{z}} \beta \gamma$ directly interferes with vesicle binding to the SNARE complex, inhibiting exocytosis.

hormones stimulate lactotroph activity, so perhaps it is wise to be doubly sure by inhibiting several targets. Also, $\mathrm{Ca}^{2+}$ has several physiological roles in addition to its role in exocytosis, such as the regulation of gene expression (34) and enzyme activation (35). So the many targets of the $\mathrm{ET}_{\mathrm{A}}$ receptor may serve many physiological purposes.

\section{References and Notes}

1. N. Ben-Jonathan, R. Hnasko, Dopamine as a prolactin (PRL) inhibitor. Endocr. Rev. 22, 724-763 (2001).

2. M. E. Freeman, B. Kanyicska, A. Lerant, G. M. Nagy, Prolactin: Structure, function, and regulation of secretion. Physiol. Rev. 80, 1523-1631 (2000).

3. S. A. Andric, D. Zivadinovic, A. E. Gonzalez-Iglesias, A. Lachowicz, M. Tomic, S. S. Stojilkovic, Endothelin-induced, long lasting, and $\mathrm{Ca}^{2+}$ influx-independent blockade of intrinsic secretion in pituitary cells by $G_{z}$ subunits. J. Biol. Chem. 280, 26896-26903 (2005).

4. K. A. Hickey, G. Rubanyi, R. J. Paul, R. F. Highsmith, Characterization of a coronary vasoconstrictor produced by cultured endothelial cells. Am. J. Physiol. 248, C550-C556 (1985).

5. M. Yanagisawa, H. Kurihara, S. Kimura, Y. Tomobe, M. Kobayashi, Y. Mitsui, Y. Yazaki, K. Goto, T. Masaki, A novel potent vasoconstrictor peptide produced by vascular endothelial cells. Nature 332, 411-415 (1988).
A

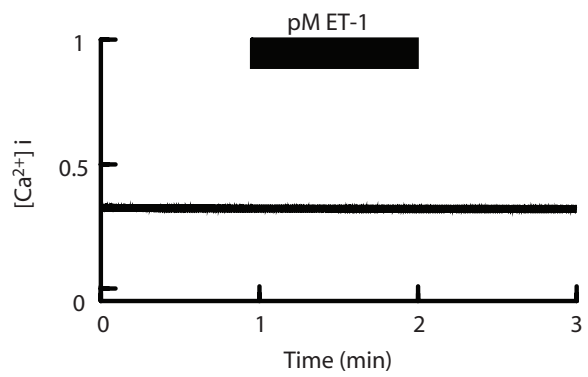

B

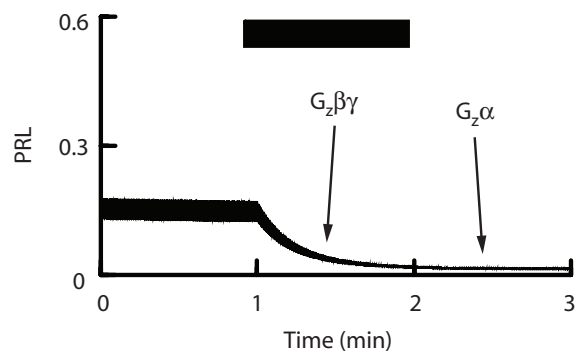

Fig. 3. Mathematical modeling of the effects of picomolar (pM) concentrations of ET-1 on lactotrophs. (A) These low concentrations have no effect on the cell's $\mathrm{Ca}^{2+}$ dynamics. (B) PRL secretion is inhibited, without the initial stimulatory spike. The cAMP concentration is also reduced at picomolar concentrations of ET-1 (not shown).

6. A. Inoue, M. Yanagisawa, S. Kimura, Y. Kasuya, T. Miyauchi, K. Goto, T Masaki, The human endothelin family: Three structurally and pharmacologically distinct isopeptides predicted by three separate genes. Proc. Natl. Acad Sci. U.S.A. 86, 2863-2867 (1989)

7. A. Sakamoto, M. Yanagisawa, T. Sakurai, Y. Takuwa, H. Yanagisawa, T. Masaki, Cloning and functional expression of human cDNA for the ET/B endothelin receptor. Biochem. Biophys. Res. Commun. 178, 656-663 (1991).

8. T. Sakurai, M. Yanagisawa, Y. Takuwa, H. Miyazaki, S. Kimura, K. Goto, T. Masaki, Cloning of a cDNA endcoding a non-isopeptide-selective subtype of the endothelin receptor. Nature 348, 732-735 (1990).

9. S. Karne, C. K. Jayawickreme, M. R. Lerner, Cloning and characterization of an endothelin-3 specific receptor (ETC receptor) from Xenopus laevis dermal melanophores. J. Biol. Chem. 268, 19126-19133 (1993).

10. B. Kanyicska, M. E. Freeman, Characterization of endothelin receptors in the anterior pituitary gland. Am. J. Physiol. 265, E601-E608 (1993).

11. M. J. Horwitz, K. D. Bloch, N. B. Kim, J. A. Amico, Expression of the endothelin-1 and oxytocin genes in the hypothalamus of the pregnant rat. Brain Res. 648, 59-64 (1994).

12. K. Naruse, M. Naruse, T. Nishikawa, I. Yoshihara, K. Ohsumi, N. Suzuki, R. Demura, $\mathrm{H}$. Demura, Endothelin-3 immunoreactivity in gonadotrophs of the human anterior pituitary. J. Clin. Endocrinol. Metab. 74, 968-972 (1992)

13. S. Hori, Y. Komatsu, R. Shigemoto, N. Mizuno, S. Nakanishi, Distinct tissue distribution and cellular localization of two messenger ribonucleic acids encoding different subtypes of rat endothelin receptors. Endocrinology 130, 1885-1895 (1992)

14. B. Kanyicska, A. Lerant, M. E. Freeman, Endothelin-like immunoreactivity in lactotrophs, gonadotrophs, and somatotrophs of rat anterior pituitary gland are affected differentially by ovarian steroid hormones. Endocrine 14 263-268 (2001)

15. B. Kanyicska, A. Lerant, M. E. Freeman, Endothelin is an autocrine regulator of prolactin secretion. Endocrinology 139, 5164-5173 (1998).

16. B. Kanyicska, T. P. Burris, M. E. Freeman, Endothelin-3 inhibits prolactin and stimulates $\mathrm{LH}, \mathrm{FSH}$ and $\mathrm{TSH}$ secretion from pituitary cell culture. Biochem. Biophys. Res. Commun. 174, 338-343 (1991).

17. W. K. Samson, K. D. Skala, B. D. Alexander, F.-L. S. Huang, Pituitary site of action of endothelin: Selective inhibition of prolactin release in vitro. Biochem. Biophys. Res. Commun. 169, 737-743 (1990).

18. W. K. Samson, K. D. Skala, Comparison of the pituitary effects of the mam- 
malian endothelins: Vasoactive intestinal contractor (endothelin-B, rat endothelin-2) is a potent inhibitor of prolactin secretion. Endocrinology 130, 2964-2970 (1992).

19. B. Kanyicska, J. D. Livingstone, M. E. Freeman, Long term exposure to dopamine reverses the inhibitory effect of endothelin-1 on prolactin secretion. Endocrinology 136, 990-994 (1995).

20. B. Kanyicska, M. E. Freeman, S. E. Dryer, Endothelin activates large-conductance $\mathrm{K}^{+}$channels in rat lactotrophs: Reversal by long-term exposure to dopamine agonist. Endocrinology 138, 3141-3153 (1997)

21. A. Lachowicz, F. Van Goor, A. C. Katzur, G. Bonhomme, S. S. Stojilkovic, Uncoupling of calcium mobilization and entry pathways in endothelin-stimulated pituitary lactotrophs. J. Biol. Chem. 272, 28308-28314 (1997).

22. P. M. Hinkle, E. J. Nelson, R. Ashworth, Characterization of the calcium response to thyrotropin-releasing hormone in lactotrophs and $\mathrm{GH}$ cells. Trends Endocrinol. Metab. 7, 370-374 (1996)

23. M. Tomic, F. Van Goor, M.-L. He, D. Zivadinovic, S. S. Stojilkovic, $\mathrm{Ca}^{2+}-$ mobilizing endothelin-A receptors inhibit voltage-gated $\mathrm{Ca}^{2+}$ influx through $\mathrm{G}_{\mathrm{i} / \mathrm{o}}$ signaling pathway in pituitary lactotrophs. Mol. Pharmacol. 61, 1329-1339 (2002).

24. M. J. Berridge, R. F. Irvine, Inositol phosphates and cell signalling. Nature 341, 197-205 (1989).

25. S. Herlitze, D. E. Garcia, K. Mackie, B. Hille, T. Scheuer, W. A. Catterall, Modulation of $\mathrm{Ca}^{2+}$ channels by G-protein $\beta \gamma$ subunits. Nature 380, 258-262 (1996).

26. S. R. Ikeda, Voltage-dependent modulation of N-type calcium channels by G-protein $\beta \gamma$ sybunits. Nature 380, 255-258 (1996).

27. D. E. Logothetis, Y. Kurachi, J. Galper, E. Neer, D. E. Clapham, Purified $\beta \gamma$ subunits of GTP-binding proteins regulate muscarinic $\mathrm{K}$ channel activity in heart. Nature 325, 321-326 (1987).

28. H. K. Fong, K. K. Yoshimoto, P. Eversole-Cire, M. I. Simon, Identification of a GTP-binding protein $\alpha$ subunit that lacks an apparent ADP-ribosylation site for pertussis toxin. Proc. Natl. Acad. Sci. U.S.A. 85, 3066-3070 (1988).

29. M. Matsuoka, H. Itoh, T. Kozasa, Y. Kaziro, Sequence analysis of cDNA and genomic DNA for a putative pertussis toxin-insensitive guanine nucleotidebinding regulatory protein $\alpha$ subunit. Proc. Natl. Acad. Sci. U.S.A. 85 5384-5388 (1988)

30. Y. H. Wong, B. R. Conklin, H. R. Bourne, $G_{z}$-mediated hormonal inhibition of cyclic AMP accumulation. Science 255, 339-342 (1992).

31. G. Nagy, K. Reim, U. Matti, N. Brose, T. Binz, J. Rettig, E. Neher, J. B. Sørensen, Regulation of releasable vesicle pool sizes by protein kinase Adependent phosphorylation of SNAP-25. Neuron 41, 417-429 (2004).

32. T. Blackmer, E. C. Larsen, C. Bartleson, J. A. Kowalchyk, E.-J. Yoon, A. M. Preininger, S. Alford, H. E. Hamm, T. F. J. Martin, G protein $\beta \gamma$ directly regulates SNARE protein fusion machinery for secretory granule exocytosis. Nat. Neurosci. 8, 421-425 (2005).

33. T. Gerachshenko, T. Blackmer, E.-J. Yoon, C. Bartleson, H. E. Hamm, S. Alford, G $\beta \gamma$ acts at the $\mathrm{C}$ terminus of SNAP-25 to mediate presynaptic inhibition. Nat. Neurosci. 8, 597-605 (2005).

34. M. Sheng, G. McFadden, M. E. Greenberg, Membrane depolarization and calcium induce $\mathrm{c}$-fos transcription via phosphorylation of transcription factor CREB. Neuron 4, 571-582 (1990).

35. S. G. Miller, M. B. Kennedy, Regulation of brain type II Ca ${ }^{2+} /$ calmodulin-dependent protein kinase by autophosphorylation: $\mathrm{A} \mathrm{Ca}^{2+}$-triggered molecular switch. Cell 44, 861-870 (1986)

36. This work was supported by NIH grant DA-19356 to R.B. and M.E.F. and by $\mathrm{NIH}$ grants DK-43200 and HD-38551 to M.E.F.

Citation: R. Bertram, J. Tabak, N. Toporikova, M. E. Freeman, Endothelin action on pituitary lactotrophs: One receptor, many GTP-binding proteins. Sci. STKE 2006, pe4 (2006). 